\title{
Público-Alvo da Educação Especial: inclusão e permanência em Colégios de Aplicação do Brasil
}

\author{
Tânia Aretuza Ambrizi Gebara ${ }^{1}$ \\ Maria Clara Regis ${ }^{2}$
}

\begin{abstract}
Resumo: Os Colégios de Aplicação (CAps), instituições vinculadas às Universidades Federais brasileiras, foram criados com o objetivo de proporcionar experimentação e inovação pedagógica. Este artigo traz resultados parciais de uma pesquisa em andamento, iniciada em 2018, que consiste na sistematização dos processos de ingresso e permanência de estudantes com deficiência nos CAps. $O$ estudo de natureza qualitativa adota como método a análise documental, com recorte temporal contemplando os anos de 2006 a 2019. O referencial teórico dialoga com: Flick (2009); Glat (2007); Forest e Pearpoint (1997). O artigo estrutura-se em três seções: a primeira aborda o desenho metodológico, trazendo um breve panorama do campo de investigação; a segunda trata dos resultados preliminares, focalizando a produção acadêmica desenvolvida pelos docentes dos CAps, com mapeamento das principais temáticas encontradas, e dos dados relativos à reserva de vagas para alunos com deficiência; a terceira seção traz considerações indicativas que contemplam as tensões $e$ desafios identificados no processo. Os resultados preliminares revelam que a inclusão escolar das pessoas com deficiência nos colégios é um processo em construção. A adoção de medidas e práticas que incentivem a produção e pesquisa acadêmica na área, que fortaleçam uma educação de qualidade para todos, ainda é um desafio.
\end{abstract}

Palavras-chave: Ingresso e permanência. Educação inclusiva. Colégios de Aplicação do Brasil.

\section{Target Audience of Special Education: inclusion and permanence in Colégios de Aplicação in Brazil}

\begin{abstract}
The Colégios de Aplicação - CAps, institutions linked to Brazilian Federal Universities, were created with the objective of providing experimentation and pedagogical innovation. This article brings partial results of an ongoing research started in 2018, which consists on the systematization of processes of entry and stay in university for students with disabilities in CAps. This qualitative study adopts documental analysis with a temporal outline that spans from 2006 to 2019. The theoretical framework
\end{abstract}

\footnotetext{
${ }^{1}$ Doutora em Educação pela Universidade Federal de Minas Gerais (UFMG). Docente do Centro Pedagógico da Escola de Educação Básica e Profissional da UFMG. E-mail: taretuza@outlook.com ou tgebara@ufmg.br ORCID iD: https://orcid.org/0000-0002-4646-3460.

${ }^{2}$ Graduanda em Letras na Universidade Federal de Minas Gerais. Professora do Projeto "Nos da Rede" do Grupo de Desenvolvimento Comunitário (GDECOM. E-mail: clara.regis@ymail.com ou mariaclararegis88@gmail.com. ORCID iD: https://orcid.org/0000-0002-0542-019X.
} 


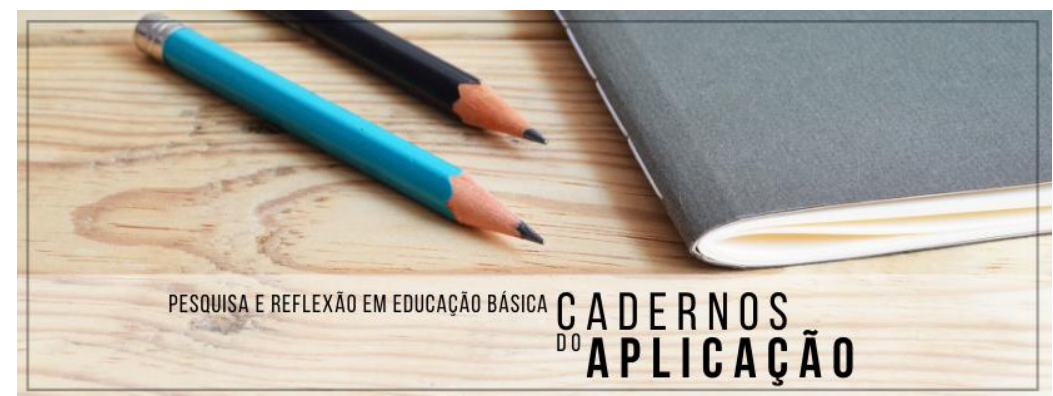

Cadernos do Aplicação

https://seer.ufrgs.br/CadernosdoAplicacao

Publicação Ahead of Print

ISSN 2595-4377 (online)

Porto Alegre | jul-dez. 2021 | v.34 | n.2

dialogues with Flick (2009); Glat (2007); Forest and Pearpoint (1997), among others. The article is structured in three sections: the first one talks about the methodological design, showing a brief panorama of the investigation field; the second is about the preliminary results, focalizing the academic production developed by CAps teachers, with mapping of the main themes found and the data relating to the reservation of vacancies for students with deficiencies. The third section brings indicative considerations that contemplate the tensions and challenges identified in the process. The preliminary results reveal that the scholar inclusion of people with deficiencies in schools is a process under construction. Under this point of view, the adoption of measures and practices that incentivize the production and academic research in the area, which strengthens quality education for all, is still a challenge.

Keywords: Enrollment and permanence. Inclusive education. Colégios de Aplicação in Brazil.

\title{
Público Destinatario de la Educación Especial: inclusión y permanencia en Colégios de Aplicação de Brasil
}

\begin{abstract}
Resumen: Los Colégios de Aplicação (CAps), instituciones vinculadas a Universidades Federales brasileñas, fueron creados con el objetivo de brindar experimentación e innovación pedagógica. Este artículo trae los resultados parciales de una investigación en marcha, iniciada en 2018, que consiste en la sistematización de los procesos de ingreso y permanencia de estudiantes con discapacidad en los CAps. El estudio de naturaleza cualitativa adopta como método el análisis documental, con recorte temporal contemplando los años de 2006 a 2019. El referencial teórico dialoga con: Flick (2009); Glat (2007); Forest y Pearpoint (1997), entre otros. El artículo se estructura en tres secciones: la primera abarca el diseño metodológico, trayendo un breve panorama del campo de investigación; la segunda trata los resultados preliminares, enfocando la producción académica desarrollada por docentes del CAps, con mapeamiento de las principales temáticas encontradas, y los datos relativos a la reserva de vacantes para alumnos con discapacidad. La tercera sección trae consideraciones indicativas que contemplan las tensiones y retos identificados en el proceso. Los resultados preliminares revelan que la inclusión escolar de personas con discapacidad en los colegios es un proceso en construcción. Bajo este punto de vista, la adopción de medidas y prácticas que incentiven la producción e investigación académica en el área, que fortalezcan una educación de calidad para todos, todavía es un desafío.
\end{abstract}

Palabras clave: Ingreso y permanencia. Educación inclusiva. Colégios de Aplicação de Brasil.

\section{Introdução}

Este artigo traz resultados preliminares referentes à pesquisa, em andamento, intitulada "Inclusão de estudantes com deficiência nos Colégios de Aplicação do Brasil”, que tem como objetivo geral sistematizar e analisar os processos de ingresso e permanência de estudantes com deficiência nos Colégios de Aplicação (CAps) brasileiros. Busca-se conhecer as formas de 
Cadernos do Aplicação

https://seer.ufrgs.br/CadernosdoAplicacao

Publicação Ahead of Print

ISSN 2595-4377 (online)

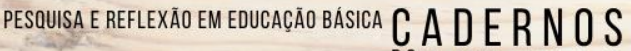

Porto Alegre | jul-dez. 2021 | v.34 | n.2

atendimento existentes no âmbito federal e, também, sistematizar a produção acadêmica dos docentes a partir de três eixos, a saber: ações de ensino, pesquisa e extensão que ocorrem nessas instituições. Portanto, o campo da investigação são os CAps vinculados às Universidades Federais do Brasil, que, atualmente, totalizam dezessete instituições, cuja finalidade é "desenvolver, de forma indissociável, atividades de ensino, pesquisa e extensão com foco nas inovações pedagógicas e na formação docente", conforme o artigo $2^{\circ}$, da Portaria n. 959, de 27 de setembro de 2013, emitida pelo Ministério da Educação (MEC).

A investigação que deu origem a este artigo é uma pesquisa de natureza qualitativa, que adota como método a análise documental, e tem como desafio conhecer, mapear e analisar a produção acadêmica referente à educação inclusiva desenvolvida e registrada formalmente por meio de projetos de pesquisa, extensão e ensino, em setores que fazem parte da organização administrativa e pedagógica dos CAps. Também, foram examinados os editais de reservas de vagas, localizando a oferta distribuída pelas diferentes regiões do país.

Sabe-se que um dos grandes desafios da educação inclusiva é assegurar a todos o direito à aprendizagem. Diante do ingresso dos alunos com deficiências nas escolas regulares, a acessibilidade curricular torna-se um ponto de entrave. A garantia da aprendizagem a sujeitos diversos, com características físicas, sensoriais, intelectuais e/ou comportamentais específicas, é um desafio. Além disso, ainda é uma lacuna conhecer o que está sendo produzido sobre a temática da educação inclusiva nos colégios federais, uma vez que essas instituições exercem o papel de agências formadoras de docentes.

O debate sobre a Educação Especial na perspectiva da educação inclusiva no Brasil tem sido intenso nos últimos anos. O estudo desenvolvido situa-se no bojo de um diálogo com o panorama legal brasileiro, no qual a inclusão de pessoas com deficiência está sendo discutida longitudinalmente ${ }^{2}$ e amplamente problematizada. É possível destacar um rol de normativas que compõem o cenário legal, por exemplo, a Resolução nº 02/2001 do CNE/CEB, que instituiu as Diretrizes Nacionais para a Educação Especial na Educação Básica e determinou a matrícula de todos os alunos no sistema regular de ensino, cabendo à escola assegurar as condições necessárias para o atendimento das crianças com necessidades educacionais especiais.

\footnotetext{
${ }^{2}$ Para saber mais, vide: SOUZA, Sidirlaia Tabeiro de. EDUCAÇÃO INCLUSIVA: avanços e desafios da acessibilidade. Trabalho de Conclusão de Curso (Bacharel em Gestão Pública) - Faculdade de Filosofia e Ciências Humanas, Universidade Federal de Minas Gerais. Minas Gerais, p. 67. 2018.
} 
Entretanto, apesar dos anos percorridos, e da promulgação, em 2015, da Lei Brasileira de Inclusão, conhecida como Estatuto da Pessoa com Deficiência, que trouxe avanços importantes - como a garantia de um ambiente inclusivo em todos os níveis da educação - tais medidas, ainda, encontram-se em fase de implementação e de tensionamento com diversos desafios.

O Ministério da Educação (MEC) revisou a atual Política Nacional de Educação Especial na Perspectiva da Educação Inclusiva (PNEEPEI), datada de 2008. O texto proposto foi analisado e tensionado por pesquisadores e educadores que tratam do assunto. Para estudiosos do tema, a nova redação voltaria a estimular a separação das pessoas com deficiência indo na contramão de inúmeras conquistas que apontam para a eliminação de barreiras, promoção da acessibilidade e não separação dos alunos com e sem deficiência.

Aliás, na Ação Direta de Inconstitucionalidade (ADI), o plenário do Supremo Tribunal Federal referendou a liminar para suspender o Decreto 10.502/2020, que instituiu a Política Nacional de Educação Especial Equitativa, Inclusiva e com Aprendizado ao Longo da Vida. Entendeu-se que tal norma poderia motivar políticas públicas que fragilizassem a inclusão de estudantes com deficiência, transtornos globais do desenvolvimento e altas habilidades ou superdotação nas redes de ensino.

Cabe ainda lembrar, nesse cenário nacional, que durante a tramitação do Plano Nacional de Educação (PNE), o qual traça 20 metas para serem cumpridas em dez anos, um ponto bastante polêmico foi a possibilidade da matrícula de crianças e jovens com deficiência em escolas especiais e não obrigatoriamente na rede regular de ensino. Na redação final da meta, aprovada em 2014, essa opção foi mantida. Organizações especializadas no tema afirmam que o texto do PNE fere tratados internacionais sobre o tema, assinados pelo Brasil. Além do Estatuto da Pessoa com Deficiência, do PNE, da Base Nacional Comum Curricular, existem decretos, portarias, resoluções, notas técnicas e leis que dispõem sobre o assunto, que refletem a evolução ou retrocesso na discussão de inclusão das diversidades. Tais documentos são observados e considerados no escopo deste artigo e da referida pesquisa em andamento.

No contexto atual, a educação inclusiva, enquanto política pública, visa romper com os atos de preconceitos historicamente praticados e aceitos pela sociedade contra as crianças e adolescentes com suas especificidades e abrange a inclusão das diversas diferenças que formam a heterogeneidade existente entre os alunos. 


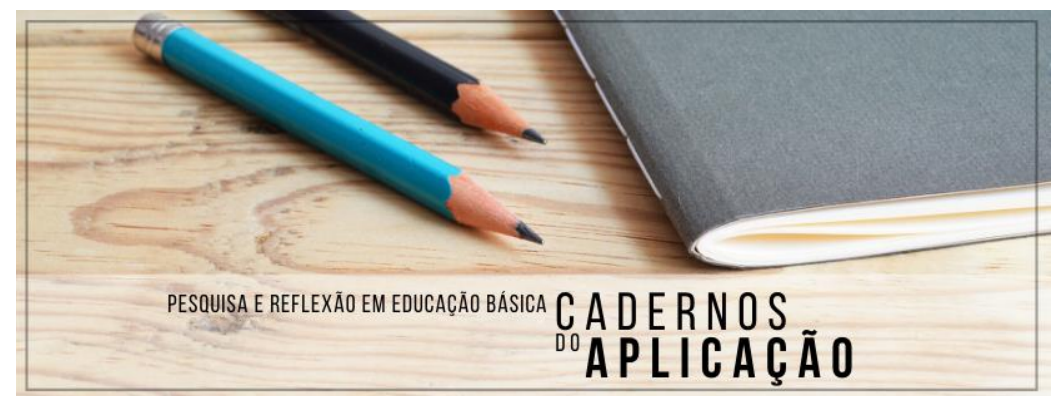

Cadernos do Aplicação https://seer.ufrgs.br/CadernosdoAplicacao

Publicação Ahead of Print

ISSN 2595-4377 (online)

Porto Alegre | jul-dez. 2021 | v.34 | n.2

Há vários autores que acumulam reflexões sobre a temática, como Mantoan (2007), que descreve a ação inclusiva via educação enquanto base dos valores humanos, na qual o outro é importante, é igual com suas diferenças em direitos e deveres. Para Carvalho (2008), a educação inclusiva considera que todos têm direitos iguais, inclusive o direito de ser diferente, não podendo haver tratamentos diferenciados em função das diferenças e sim tratamentos especializados que consideram essas especificidades.

Conforme Rodrigues (2008), a educação inclusiva é uma reforma educativa, caracterizada pela renovação das práticas educativas, que busca desenvolver valores educacionais democráticos de convivência com a diversidade, em que todos aprendem juntos respeitando as suas especificidades. Segundo Forest e Pearpoint (1997), a educação inclusiva não significa apenas colocar uma criança com deficiência na sala de aula ou na escola regular. Com o mesmo pensamento, Dutra (2008) define que a educação inclusiva:

[...] constitui um paradigma fundamentado na concepção de direito humanos, que conjuga igualdade e diferença como valores indissociáveis e supera o modelo de equidade formal, passando a incidir para eliminar as circunstâncias históricas da produção da exclusão dentro e fora da escola.[...]

[...] A partir destes pressupostos, modificam-se os conceitos, a legislação, as práticas educacionais e de gestão, para promover a reestruturação dos sistemas de ensino e acolher todos os alunos, independente de condição social, cultural, linguística, étnico-racial, de orientação sexual, de gênero, de característica física, intelectual ou emocional e outras (DUTRA, 2008, p. 28).

A educação inclusiva, portanto, propõe transformar a escola em um espaço para todos, no qual a diversidade é inserida por considerar a necessidade especial momentânea ou permanente dos alunos. Na prática, a educação inclusiva consiste no atendimento de toda diversidade de alunos em escolas com atendimento regular de ensino, considerando a especificidade do contexto social e cultural e as peculiaridades advindas da condição de cada aluno. De acordo com Aranha (2001), educação inclusiva é quando a escola aceita e convive com a diversidade e este convívio com as diferenças proporciona oportunidades de crescimento para todos e, principalmente, condições para os alunos com necessidades especiais de viver em sociedade e usufruir dos mesmos direitos.

Conforme mencionado anteriormente, os debates sobre a inclusão das crianças com deficiência, transtornos do desenvolvimento, altas habilidades ou superdotação no ensino 
regular têm sido tensos, uma vez que somente a lei não garante a efetivação concreta da permanência desses alunos na escola, sendo um processo, portanto, instituído com conflitos e tensões. A inclusão de sujeitos com deficiência no ensino regular ainda faz parte dos grandes desafios da atualidade. Nesse sentido, a análise crítica sobre a forma de como tem sido realizada a inclusão escolar desse público constitui tema de trabalhos como os de Glat (2011); Glat e Pletsh (2012) e Pletsch (2012).

Pensar a diversidade, então, configura-se em uma visão ampla de mundo, pois, o ser humano precisa ser formado em sua totalidade, de forma que suas diferenças sejam respeitadas e consideradas, com a garantia do respeito dos outros em suas diferenças e necessidades. A formação do ser humano em sua totalidade perpassa o conjunto das práticas desenvolvidas na escola, nas quais as suas especificidades precisam ser encaradas para criação de um ambiente propício e acolhedor das diversidades dos alunos. Sendo assim, a adequação da escola torna-se necessária para possibilitar não apenas o acesso, mas também a permanência e o desenvolvimento do aluno com sua particularidade, tornando-se, de fato, uma escola inclusiva.

O debate sobre o acesso e a permanência de estudantes com deficiência é pauta de interesse dos CAps, que pertencem ao sistema público de ensino federal e que também atuam como agências formadoras de docentes e discentes. É no bojo dessas reflexões que este artigo tem acento e busca comunicar parcialmente os dados coletados e resultados preliminares elaborados durante a pesquisa sobre o tema.

Este artigo estrutura-se em três seções: a primeira aborda o desenho metodológico, trazendo um breve panorama do campo de investigação; a segunda trata das produções acadêmicas desenvolvidas pelos docentes dos colégios e publicadas em seus respectivos periódicos on-line, além de dados referentes à reserva de vagas nos dezessete colégios. Por fim, a terceira seção traz considerações indicativas que contemplam as tensões e os desafios identificados no processo da pesquisa.

\section{Campo da pesquisa e procedimentos metodológicos: percursos realizados}

Em relação à metodologia utilizada, trata-se de uma investigação que tem como método a análise documental, sendo uma pesquisa de natureza qualitativa. Lüdke (1986, p.5) justifica 


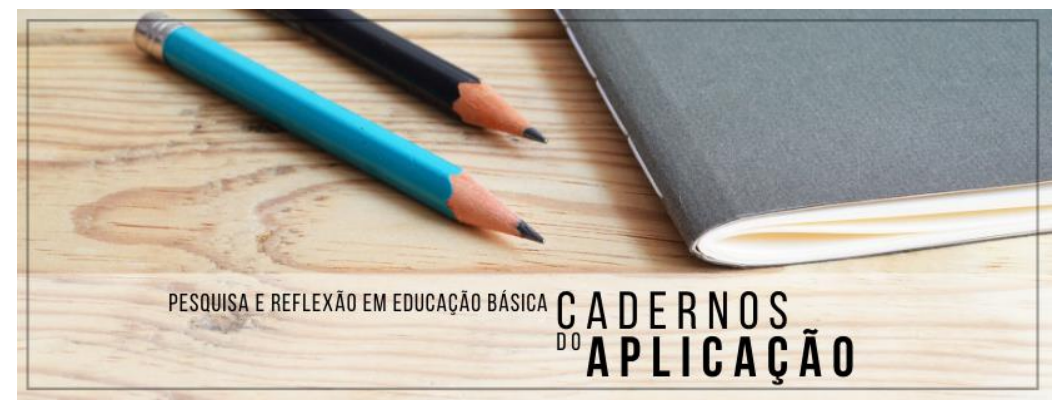

Cadernos do Aplicação

https://seer.ufrgs.br/CadernosdoAplicacao

Publicação Ahead of Print

ISSN 2595-4377 (online)

Porto Alegre | jul-dez. 2021 | v.34 | n.2

a utilização de metodologias qualitativas, visto que os fenômenos educacionais são muito complexos: "cada vez mais se entende o fenômeno educacional como situado dentro de um contexto social, por sua vez inserido em uma realidade histórica, que sofre toda uma série de determinações" (LÜDKE ,1986, p.5).

Compreende-se, no entanto, que somente uma abordagem qualitativa não seria capaz de abranger e analisar todos os dados. Diante disso, o estudo utiliza abordagens quantitativas em algumas fases dos processos, e tais métodos são articulados e analisados. Flick (2009, p.43) já alertava sobre a possibilidade de associação dos métodos qualitativos e quantitativos:

E, por fim, nenhum dos métodos combinados é visto como sendo superior ou preliminar. Quer os métodos sejam ou não utilizados simultaneamente, ou empregados um após o outro, este é um aspecto menos relevante se comparado à noção de serem vistos em igualdade quanto ao papel que desempenham no projeto (FLICK, 2009, p. 43).

Nesse viés, a metodologia de investigação adotada é a análise documental. Flick (2009, p.231) oferece uma definição do que se entende como documento na pesquisa qualitativa mais dinâmica e mais voltada para prática:

Se tivermos que arcar com a natureza dos documentos, então precisaremos afastar-nos de um conceito que os considere como artefatos estáveis, estáticos e pré-definidos. Em vez disso, devemos considerá-los em termos de campos, de estruturas e de redes de ação. De fato, o status das coisas enquanto "documentos" depende precisamente das formas como esses objetos estão integrados nos campos de ação, e os documentos só podem ser definidos em relação a esses campos (FLICK, 2009, p. 231).

Com base no conceito adotado por Flick (2009, p. 43-231), são considerados como fontes documentais: os projetos de ensino, pesquisa e extensão cadastrados nos setores pedagógicos e administrativos dos CAps; o Projeto Político Pedagógico de cada instituição; os editais normativos para ingresso de novos alunos; documentos de domínio público, disponíveis nas páginas web dos colégios.

A pesquisa encontra-se em andamento e foi dividida em duas etapas, a saber: coleta dos dados e análise do conteúdo. A coleta dos dados aconteceu por meio da internet. As pesquisadoras interagiram com a produção acadêmica por intermédio da quantificação e da 


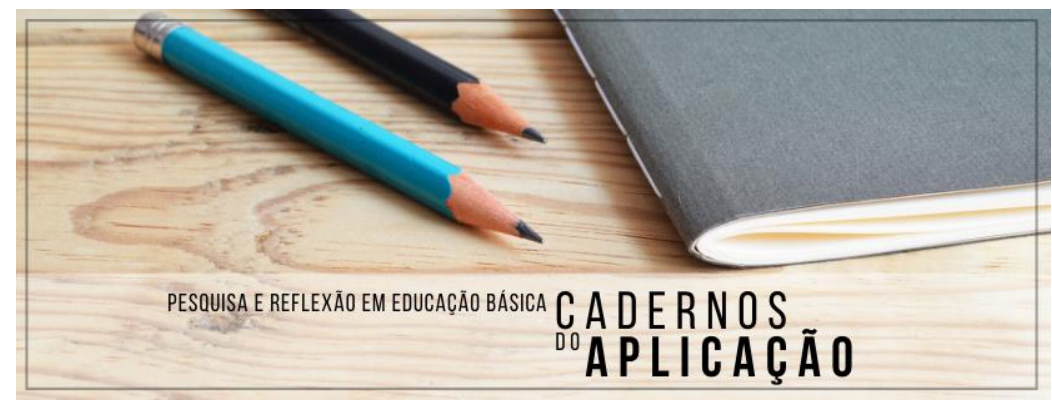

Cadernos do Aplicação

https://seer.ufrgs.br/CadernosdoAplicacao

Publicação Ahead of Print

ISSN 2595-4377 (online)

Porto Alegre | jul-dez. 2021 | v.34 | n.2

identificação dos dados, com o intuito de fazer um mapeamento da produção no período delineado (2006-2019), em anos, locais e áreas de produção ou eixos de trabalho.

É importante esclarecer que foi realizado um amplo levantamento bibliográfico abordando os periódicos dos colégios. A intenção, ao elaborar o desenho da pesquisa, era de não apenas limitar a investigação ao tema referente ao acesso dos estudantes público-alvo da educação especial nos CAps, mas também abordar os debates sobre a permanência com qualidade. Dessa forma, foi relevante conhecer sobre os conhecimentos e saberes que os docentes dos Colégios de Aplicação do Brasil estão produzindo sobre o tema da inclusão escolar. Buscou-se investigar: quais temas são priorizados pelos docentes dos CAps? Há temas de interesse comum entre os docentes? Em quais periódicos as produções dos docentes são socializadas? Essas foram algumas das indagações formuladas que parcialmente serão discutidas neste artigo.

Com tal fim, foram, inicialmente, mapeadas as revistas dos próprios colégios. Tabulouse todos os periódicos on-line existentes e disponíveis digitalmente, buscando identificar a existência de periódicos indexados.

Em seguida, iniciou-se a análise dos documentos coletados. Nessa fase, foi necessário um esforço para detalhamento da produção, além da organização do material, que pressupõe uma leitura completa ou parcial das fontes para que elas pudessem ser categorizadas. Após esse processo, estão sendo realizadas escolhas metodológicas e teóricas aproximando ou diferenciando os trabalhos entre si.

Conforme explicitado, o campo de estudo da pesquisa são os dezessete Colégios de Aplicação Federal (CAPs), vinculados a universidades federais, conforme tabela abaixo. 
Cadernos do Aplicação https://seer.ufrgs.br/CadernosdoAplicacao Publicação Ahead of Print ISSN 2595-4377 (online)

PesQuisa e ReFLeXÃo em EdUCAC̄ão básica $C$ A D E R N O S

${ }^{0} A P L I C A C ̧ A ̃ O$

Figura 1 - Lista de Colégios de Aplicação vinculados a universidades federais

\begin{tabular}{|c|c|}
\hline $\begin{array}{l}\text { UNIVERSIDADES } \\
\text { FEDERAIS }\end{array}$ & UNIDADE DE EDUCAÇÃO BÁSICA \\
\hline UFPA & ESCOLA DE APLICAÇÃO DA UFPA \\
\hline UFRN & NÚCLEO DE EDUCAÇÃO DA INFÂNCIA \\
\hline UFPE & COLÉGIO DE APLICAÇÃO DA UFPE \\
\hline UFS & COLÉGIO DE APLICAÇÃO - CODAP \\
\hline UFJF & COLÉGIO DE APLICAÇÃO JOÃO XXIII \\
\hline UFV & COLÉGIO DE APLICAÇÃO - COLUNI \\
\hline UFU & ESCOLA DE EDUCACૃÁO BÁSICA - ESEBA \\
\hline UFRJ & COLÉGIO DE APLICAÇÃO DA UFRJ \\
\hline UFRGS & COLÉGIO DE APLICAÇÃO DA UFRGS \\
\hline UFSC & COLÉGIO DE APLICAÇÃO DA UFSC \\
\hline UFSC & NÚCLEO DE DESENVOLVIMENTO INFANTIL - NDI \\
\hline UFG & $\begin{array}{l}\text { CENTRO DE ENSINO E PESQUISA APLICADA A } \\
\text { EDUCAÇÃO - CEPAE }\end{array}$ \\
\hline UFMG & $\begin{array}{l}\text { CENTRO PEDAGÓGICO DA ESCOLA DE } \\
\text { EDUCAÇÃO BÁSICA E PROFISSIONAL DA UFMG }\end{array}$ \\
\hline UFMA & COLÉGIO UNIVERSITÁRIO - COLUN \\
\hline UFRR & COLÉGIO DE APLICAÇÃO DA UFRR \\
\hline UFF & COLÉGIO UNIVERSITÁRIO GERALDO REIS \\
\hline UFAC & COLÉGIO DE APLICAÇÃO DA UFAC \\
\hline
\end{tabular}

Fonte: Elaborado pelas autoras.

No que se refere a localização dos CAps, nota-se que os colégios se distribuem nas cinco regiões do Brasil e concentram-se em sua maioria na região Sudeste do país, que conta com um total de seis CAps instalados. A região Nordeste conta com quatro colégios e as regiões Norte e Sul contam com três cada. Já na região Centro-Oeste, há somente um. A distribuição dos CAps por região pode ser também visualizada abaixo: 


\section{Figura 2 - Distribuição dos CAps no Brasil}

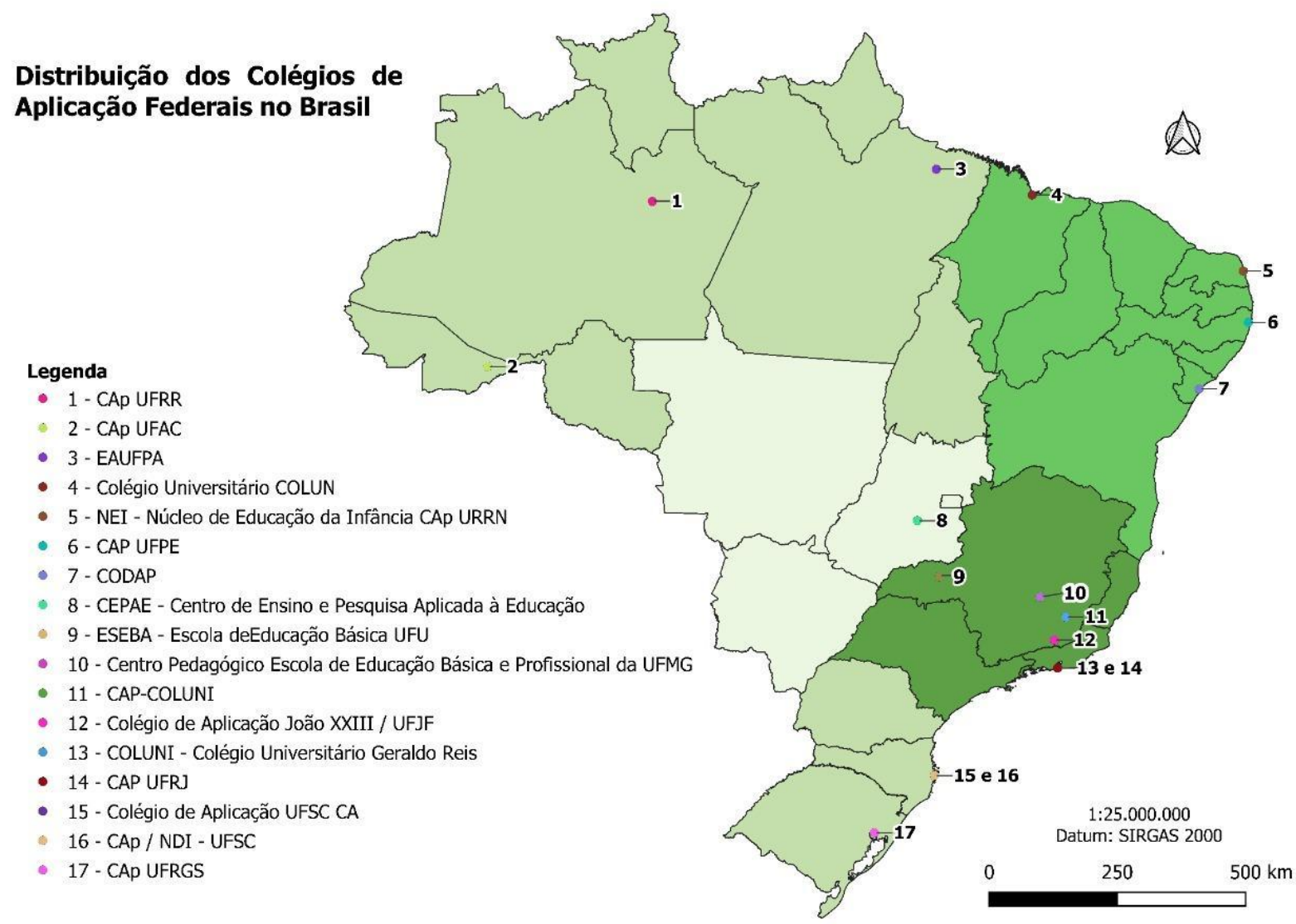

Fonte: Elaborado pelas autoras.

Em relação às modalidades de ensino ofertadas pelos CAps, nota-se que há oferta de todos os segmentos da educação básica. O segmento da educação infantil é ofertado em sete dos 17 CAps. Em relação ao ensino fundamental, temos algumas peculiaridades: 11 instituições ofertam-no integralmente, ou seja, os nove anos regulamentares; enquanto um oferta o ensino fundamental I; e três dedicam-se à oferta do ensino fundamental II. Outros dois CAps não oferecem tal segmento.

Já o ensino médio representa a modalidade mais ofertada pelas instituições, totalizando 12. A modalidade de ensino Educação de Jovens e Adultos é ofertada por cinco dos CAps investigados. Apenas um CAp oferta todos os segmentos da educação básica e EJA.

Em termos percentuais, os dados são: $41 \%$ ofertam educação infantil; $65 \%$ ensino fundamental completo, sendo que 6\% dos CAps ofertam apenas ensino fundamental I e $18 \%$ 
Cadernos do Aplicação

https://seer.ufrgs.br/CadernosdoAplicacao

Publicação Ahead of Print

ISSN 2595-4377 (online)

Pesquisa e ReFlexão em EduCAÇ̃̃o básica $C$ A D E R N OS

${ }^{0} A P L I C A C ̧ A ̃ O$

Porto Alegre | jul-dez. 2021 | v.34 | n.2

dos Colégios de Aplicação apenas o ensino fundamental II; já 70\% das instituições oferecem ensino médio e somente $24 \%$ ensino de jovens e adultos (EJA).

Em relação às formas de ingresso nessas instituições, observa-se que prevalece a forma democrática de acesso, por meio de sorteio público via edital. Assim, 76\% dos colégios optam por essa modalidade e $24 \%$ realizam processo seletivo.

\section{Figura 3 - Ingresso nos CAps \\ Formas de ingresso nos CAps}

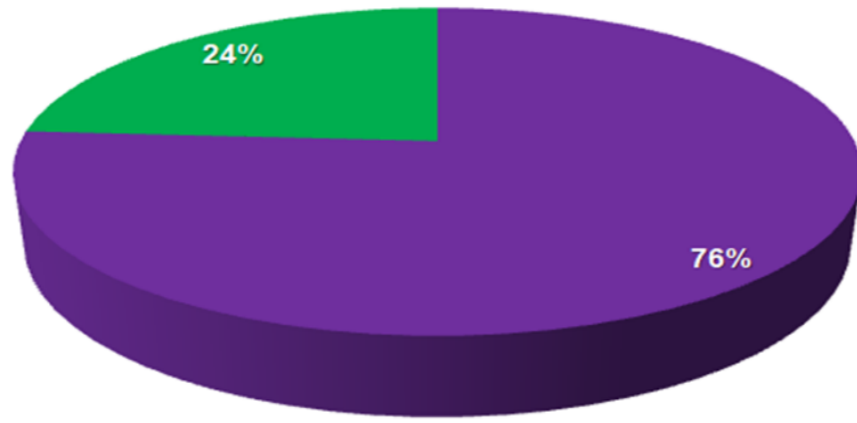

" Sorteio público via edital a Processo seletivo

Fonte: Elaborado pelas autoras.

Em suma, a partir do breve levantamento realizado, identifica-se que os CAps se concentram na região Sudeste, há a oferta de todos os segmentos da educação básica, prevalecendo o ensino médio como modalidade mais ofertada e o sorteio público via edital como forma de ingresso mais praticada. Conhecer o perfil dos colégios contribui para entender e analisar os dados da pesquisa em andamento de forma mais assertiva. Entretanto, além disso, é importante frisar que conhecer os Colégios de Aplicação existentes no Brasil ainda é um desafio, pois há pouca literatura sobre essas instituições.

Após esse breve panorama sobre o campo de investigação, que são os Colégios de Aplicação, serão focalizados a seguir os resultados preliminares referentes às produções acadêmicas dos docentes dos CAps, publicadas em seus respectivos periódicos on-line, com destaque para o mapeamento das principais temáticas encontradas, além dos dados relativos à reserva de vagas para alunos público-alvo da educação especial. 


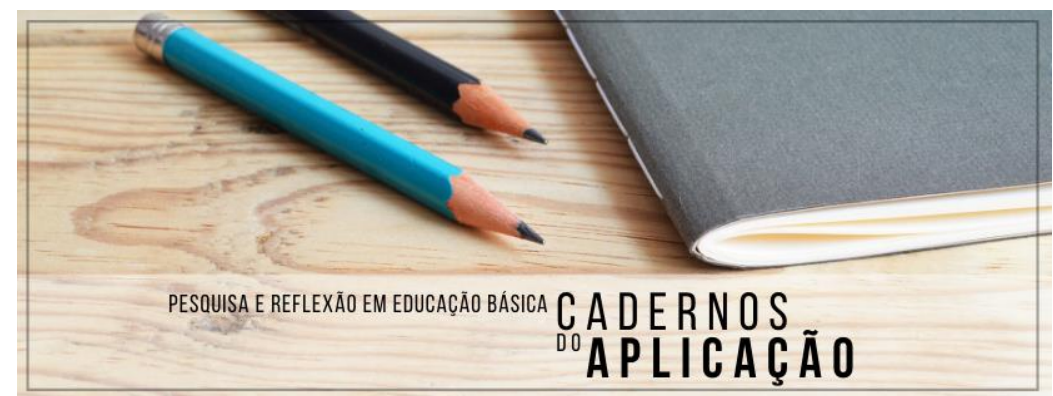

Cadernos do Aplicação https://seer.ufrgs.br/CadernosdoAplicacao Publicação Ahead of Print ISSN 2595-4377 (online) Porto Alegre | jul-dez. 2021 | v.34 | n.2

\section{Resultados preliminares}

O estabelecimento da educação inclusiva como política educacional do país coloca em questionamento os pressupostos que consubstanciavam a escola como tradicionalmente a conhecemos (GLAT, 2007). A escola passa a ser, por princípio, uma instituição social a que todos têm direito de acesso e permanência, tendo sob a sua responsabilidade oferecer um ensino de qualidade para todos os alunos.

Com a intenção de diminuir a segregação social, as políticas públicas de inúmeros países, inclusive do Brasil, incentivam a implantação de programas para integração de crianças com deficiência no sistema regular de ensino. Embora venha ocorrendo, gradativamente, a inclusão no ensino regular, os problemas de relacionamento social e de aprendizagem ainda permanecem graves. A produção de Glat (2007) aprofunda o debate sobre os modelos de integração e inclusão, bem como as suas implicações para a cultura e o cotidiano escolar.

Tornar a educação mais inclusiva tem sido um grande desafio para as instituições de ensino, pois uma gama de condições torna-se necessária: estrutura de atendimento para as necessidades dos estudantes; professores dispostos a adaptar a forma de trabalhar; trabalho com toda a comunidade escolar para o acolhimento e clareza sobre os processos de ensino, aprendizagem e avaliação. Assim, construir sistemas com propostas educacionais inclusivas exige transformações nas práticas escolares.

Ciente de todos esses aspectos, é importante esclarecer que, neste artigo, busca-se reunir contribuições que abordem o tema do acesso dos estudantes público-alvo da educação especial na perspectiva da educação inclusiva, e refletir sobre os debates sobre a permanência com qualidade. Com tal fim, foram inicialmente mapeadas as revistas dos próprios colégios, no intuito de verificar as produções dos docentes sobre o tema. Tabulou-se todos os periódicos online existentes e disponíveis digitalmente, buscando identificar a existência de periódicos indexados. As buscas se deram por meio de palavras-chave relacionadas à temática da educação especial na perspectiva da educação inclusiva e o recorte temporal utilizado foi do ano de 2006 até o ano de 2019. Os principais resultados foram: 
Figura 4 - Revistas dos CAps

\begin{tabular}{|c|c|c|}
\hline Colégio de Aplicação & Nome da Revista & Qualis \\
\hline Escola de Aplicação da UFPA & Cadernos de Ensino & \\
\hline \multirow{2}{*}{$\begin{array}{l}\text { Colégio de Aplicação João XXIII - } \\
\text { UFJF }\end{array}$} & Argo & \\
\hline & $\begin{array}{l}\text { Instrumento - Revista em } \\
\text { Estudo e } \\
\text { Pesquisa em Educação }\end{array}$ & B4 \\
\hline CAp - UFRGS & Cadernos do Aplicação & C \\
\hline Cap - UFAC & $\begin{array}{l}\text { South American Journal of } \\
\text { Basic } \\
\text { Education, Technical and } \\
\text { Technological }\end{array}$ & B1 \\
\hline CEPAE- UFG & Revista Polyphonía & \\
\hline CAp- UFSC & Revista Tudo Sobre & \\
\hline $\begin{array}{l}\text { Escola de Educação Básica - } \\
\text { ESEBA -UFU }\end{array}$ & $\begin{array}{l}\text { Olhares e Trilhas da } \\
\text { Escola de } \\
\text { Educação Básica da } \\
\text { Universidade } \\
\text { Federal de Uberlândia } \\
\text { (ESEBA / UFU) }\end{array}$ & \\
\hline CAp- UFV & Revista Ponto de Vista & \\
\hline
\end{tabular}

Fonte: Elaborado pelas autoras.

Dessa forma, identificou-se uma produtividade ainda incipiente em relação ao tema da educação inclusiva, uma vez que a temática da inclusão de pessoas público-alvo da educação especial aparece de forma muito pouco expressiva na produção acadêmica das instituições, inclusive, em suas próprias revistas on-line. Entretanto, alguns colégios destacam-se, como o Centro de Ensino e Pesquisa Aplicada à Educação - CEPAE vinculado à Universidade Federal de Goiás (UFG) com 37 produções sobre o tema em sua revista. 


\section{Figura 5 - Produção Acadêmica dos CAps}

\section{REVISTAS ONLINE e PUBLICAÇÃO NA TEMÁTICA (2006 - 2019) \\ - PUBLICAÇÃo NA TEMÁTICA r REVISTAS ONLINE}

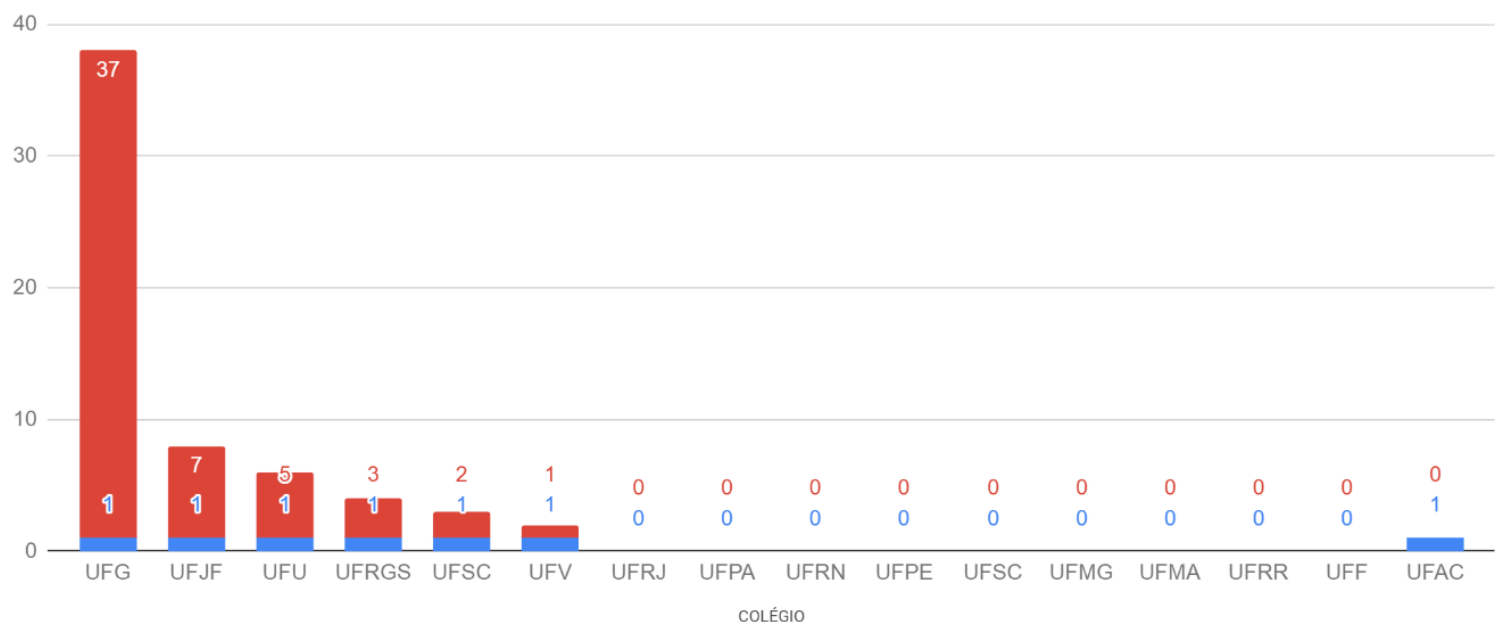

Fonte: Elaborado pelas autoras.

Vale ressaltar que os dados foram colhidos em meios digitais, excluindo-se, assim, publicações em meios físicos, caso existam.

Segundo as informações coletadas, seis Colégios de Aplicação Federal publicaram sobre inclusão de pessoas com deficiência: em primeiro lugar, o colégio vinculado a UFG com 37 publicações, desde 2006; seguido pelos colégios da UFJF com sete publicações; UFU com cinco; UFRGS com três; UFSC com duas produções, e, por fim, UFV com uma publicação na área. Nos demais colégios, não estão disponíveis publicações que abordem os temas de pessoas com deficiência, educação inclusiva ou especial.

Outrossim, também foram identificados os principais eixos temáticos de produtividade. Ao todo foi possível sistematizar as publicações em 12 eixos temáticos. Dentre esses temas, existe uma maior incidência no eixo "Educação inclusiva e prática pedagógica/ Inclusão do aluno com deficiência na sala de aula", seguido por "Atendimento Educacional Especializado: uma nova proposta de educação inclusiva" e "Recursos de tecnologia assistiva / Adaptações e inovações educacionais/ Políticas de Acessibilidade". A tabela abaixo ilustra melhor esse quantitativo de produções nas temáticas identificadas. 
Figura 6 - Quantitativo de temáticas abordadas pelos CAps

\begin{tabular}{|c|c|}
\hline TEMÁTICAS ABORDADAS & QUANTITATIVO \\
\hline $\begin{array}{l}\text { Educação inclusiva e prática pedagógica/ Inclusão do aluno com } \\
\text { deficiência na sala de aula }\end{array}$ & 10 \\
\hline $\begin{array}{l}\text { Atendimento Educacional Especializado: uma nova proposta de } \\
\text { educação inclusiva }\end{array}$ & 8 \\
\hline $\begin{array}{l}\text { Recursos de tecnologia assistiva / Adaptações e inovações } \\
\text { educacionais/ Políticas de Acessibilidade }\end{array}$ & 8 \\
\hline $\begin{array}{l}\text { O professor mediador e o processo de aprendizagem do aluno com } \\
\text { deficiência }\end{array}$ & 6 \\
\hline $\begin{array}{l}\text { A Língua Brasileira de Sinais como inclusão social dos surdos no } \\
\text { sistema educacional }\end{array}$ & 5 \\
\hline Inclusão de alunos com deficiência na Educação Infantil & 5 \\
\hline $\begin{array}{l}\text { Formação de professores na perspectiva da inclusão escolar da } \\
\text { pessoa com deficiência }\end{array}$ & 4 \\
\hline Inclusão de alunos com deficiência nas aulas de Educação Física & 4 \\
\hline $\begin{array}{l}\text { Concepções de deficiência: um estudo sobre a representação social } \\
\text { da diversidade humana ao longo da história }\end{array}$ & 3 \\
\hline $\begin{array}{l}\text { Organização da atividade de ensino a partir do desenho universal de } \\
\text { aprendizagem/ Criação de Livro Digital Universal para pessoas com } \\
\text { deficiência }\end{array}$ & 1 \\
\hline $\begin{array}{l}\text { Jovens surdos em processo de formação educacional: atores de uma } \\
\text { cultura própria }\end{array}$ & 1 \\
\hline Estudo sobre os transtornos e deficiências / Limitações dos alunos & 1 \\
\hline
\end{tabular}

Fonte: Elaborado pelas autoras.

A prevalência dos eixos temáticos citados acima, permite refletir sobre a hipótese de que as temáticas se mostram coerentes com os avanços na legislação brasileira, uma vez que, com a Lei Brasileira de Inclusão (2015), as escolas devem oferecer atendimento especializado e garantir acessibilidade dos seus alunos, além de assegurar um ambiente inclusivo em todos os níveis de formação.

Dentre os três eixos temáticos de maior incidência na produção acadêmica dos docentes dos CAps, buscou-se identificar aproximações entre os artigos localizados. Verificou-se que sobre o tema das práticas em sala de aula, os autores abordam a tendência mundial em se viabilizar o ensino na diversidade; a presença de dificuldades na efetivação de propostas no âmbito macro da escola; a necessidade de formar parcerias com outros docentes e com as famílias; o levantamento e identificação de demandas locais; a avaliação de medidas, 
procedimentos e resultados das práticas na área da inclusão educacional; o investimento em novas tecnologias. Enfim, várias dessas considerações foram feitas ao longo dessas produções e todas as obras indicaram, de maneira geral, a urgência de mudanças no sistema educacional, bem como a emergência de novos paradigmas de organização do ambiente da sala de aula. Cabe ainda destacar que as práticas docentes em sala de aula são abordadas como um todo, o que lhes conferem sentido e direção que fortalecem o lócus do docente dos CAps enquanto sujeitos que realizam ensino e ao mesmo tempo se envolvem com ações do campo da pesquisa e extensão. Isso é mencionado em parte dos artigos analisados como aspecto que dá uma identidade singular para o professor pesquisador que atua com o tema da inclusão escolar.

Com relação ao tema do atendimento educacional especializado, notou-se que, em comum, todos os artigos trazem um forte destaque sobre o panorama legal, apontando praticamente os mesmos documentos oficiais, tais como: Constituição/88, ECA/90, Lei $\mathrm{N}^{\circ}$ 10.845, de 5 de março de 2004, que institui o Programa de Complementação ao Atendimento Educacional Especializado às Pessoas Portadoras de Deficiência, e dá outras providências; Lei de Diretrizes e Bases da Educação Nacional, LDB, ou Lei No 9394, promulgada em 1996; a Resolução No 4, de 2 de outubro de 2009, do CNE/CEB, que institui as Diretrizes Operacionais para o Atendimento Educacional Especializado - AEE na Educação Básica, orientando a organização desse atendimento na rede pública ou comunitária, confessional ou filantrópica sem fins lucrativos.

Em suma, os artigos sobre o Atendimento Educacional Especializado (AEE) consistem, portanto, em um conjunto de atividades pedagógicas e de recursos de acessibilidade que são organizados e utilizados estrategicamente, considerando as necessidades específicas do aluno atendido. Nesse sentido, o AEE é elaborado de acordo com o currículo da escola e ministrado em alguns locais por profissionais com formação nesse tipo de atendimento. O tema é abordado apontando aspectos sobre a finalidades do AEE, perfil e atuação dos professores. Essas produções trazem também a demanda de ampliação de redes de apoio e suportes diferenciados para os estudantes com deficiência. Nesse cenário, registra-se também um debate sobre a necessidade de esclarecer sobre as atribuições mais bem definidas, sobre o perfil profissional específico e condições de trabalho, bem como a interlocução desses aspectos com as políticas de escolarização, que apontam alguns contextos escolares conflituosos e a necessidade de 
fortalecer as estratégias de organização dos trabalhos escolares sem gerar mecanismos de barateamento e simplificação do sistema de apoio.

Sobre o terceiro eixo temático referente às tecnologias assistivas/adaptações e inovações/políticas de acessibilidade, os artigos trazem uma discussão referente ao papel das tecnologias assistivas como ferramentas importantes na construção do conhecimento, que possibilitam melhor comunicação e as colocam como alternativas para mudar o modelo que ainda prevalece nos sistemas educacionais brasileiros, baseado na repetição e na cópia e que, não tem garantida a obtenção de sucesso escolar. Ainda apresentam as tecnologias assistivas, os recursos de adaptação do ensino e as inovações como possibilidade e necessidade para um ensino inclusivo que respeite as diferenças. As produções, nesse eixo, também ressaltam a necessidade de qualificação dos professores associada à demanda por adaptação das escolas quanto às condições físicas, mobiliário, equipamentos e materiais pedagógicos, além da criação de incentivos e a retirada de todo obstáculo para que os estudantes permaneçam no sistema escolar. Com relação à política de acessibilidade, nota-se que os artigos examinados dão destaque ao conceito de acessibilidade na educação inclusiva, registrando que, além do conceito de ir e vir, que consiste na possibilidade de locomoção sem barreiras, de ter acesso a múltiplos ambientes com independência, segurança e autonomia, bem como o acesso à comunicação e a informação de forma adequada às necessidades de cada aluno. Nos aportes teóricos utilizados em artigos mais recentes, nota-se que a acessibilidade não se restringe ao espaço físico, ou seja, a dimensão arquitetônica, classifica-se a acessibilidade também nas dimensões comunicacionais, atitudinais, programáticas, metodológicas e instrumentais.

Com relação aos dados coletados referentes à reserva de vagas destinadas a alunos com deficiência, foram analisados os editais para entradas em 2018 e 2019. Nesse contexto, para entrada em 2018, foram ofertadas, ao total, mapeando os dezessete CAps, 982 vagas com apenas 30 reservadas aos alunos público-alvo da educação especial, ou seja, somente 3\%. Esse cenário não sofreu grandes transformações para entradas em 2019, visto que do total de 1.011 vagas ofertadas, apenas 42 foram reservadas para os deficientes, o que corresponde a 4,15\%. Apesar do aumento no percentual de um ano para outro, os números ainda não são muito significativos, o que pode ser visto no gráfico abaixo: 
Cadernos do Aplicação https://seer.ufrgs.br/CadernosdoAplicacao Publicação Ahead of Print ISSN 2595-4377 (online) Pesquisa e ReFlexão em EdUCAC̄ão básica C A D E R N OS ${ }^{00}$ A PLICAÇÃO

Figura 7 - Reserva de vagas nos CAps

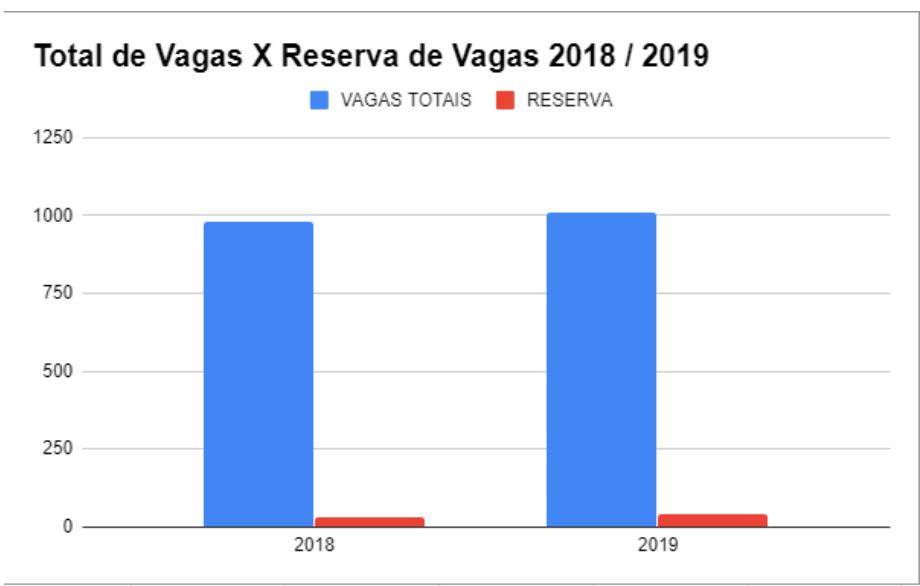

Fonte: Elaborado pelas autoras.

Dentre os 17 colégios vinculados às universidades federais brasileiras, no período analisado, oito apresentaram reservas de vagas para alunos com deficiência. Os colégios identificados são: dois da região Sul; dois da região Norte; dois da região Nordeste e dois da região Sudeste.

Figura 8 - Reserva de vagas nos CAps

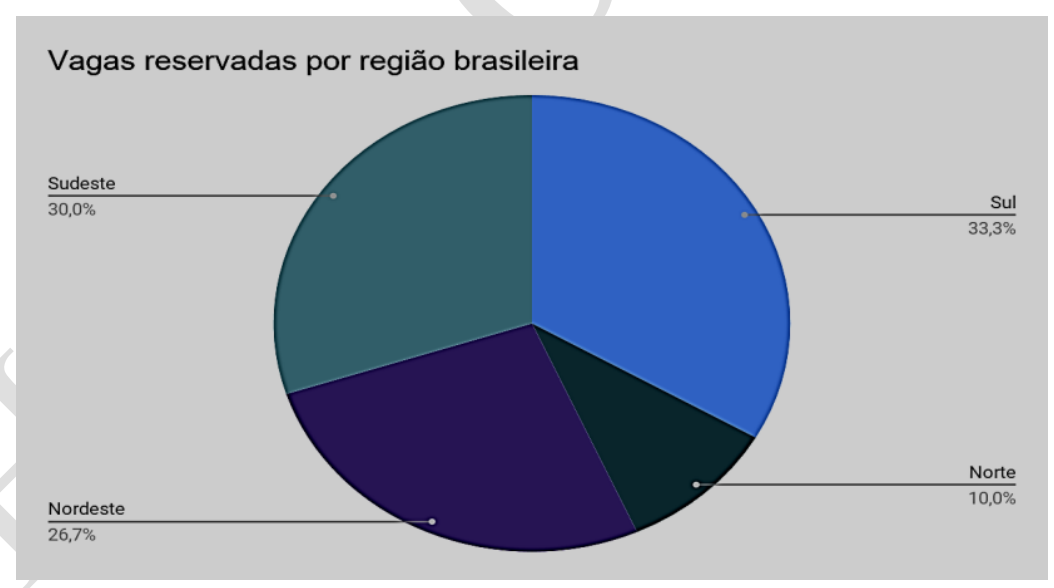

Fonte: Elaborado pelas autoras.

As informações por região, discriminação dos colégios, apresentação das vagas reservadas comparadas ao total de vagas existentes e o percentual correspondente podem ser vistas abaixo por meio da tabela e do gráfico: 
Cadernos do Aplicação https://seer.ufrgs.br/CadernosdoAplicacao Publicação Ahead of Print ISSN 2595-4377 (online)

Figura 9 - Vagas Totais e Vagas Reservadas nos CAps

\begin{tabular}{|c|c|c|c|}
\hline CAps & $\begin{array}{c}\text { Vagas } \\
\text { ofertadas }\end{array}$ & $\begin{array}{c}\text { Vagas } \\
\text { reservadas }\end{array}$ & Percentuais \\
\hline UFSC - CAp & 57 & 3 & $5 \%$ \\
\hline UFSC - NDI & 60 & 7 & $10 \%$ \\
\hline UFRR & 10 & 1 & $10 \%$ \\
\hline UFPA & 35 & 2 & $6 \%$ \\
\hline UFMA & 148 & 7 & $5 \%$ \\
\hline UFRN & 37 & 1 & $4 \%$ \\
\hline UFU & 60 & 6 & $10 \%$ \\
\hline UFMG & 50 & 3 & $5 \%$ \\
\hline
\end{tabular}

Fonte: Elaborado pelas autoras.

Figura 10 - Distribuição de vagas por regiões do país

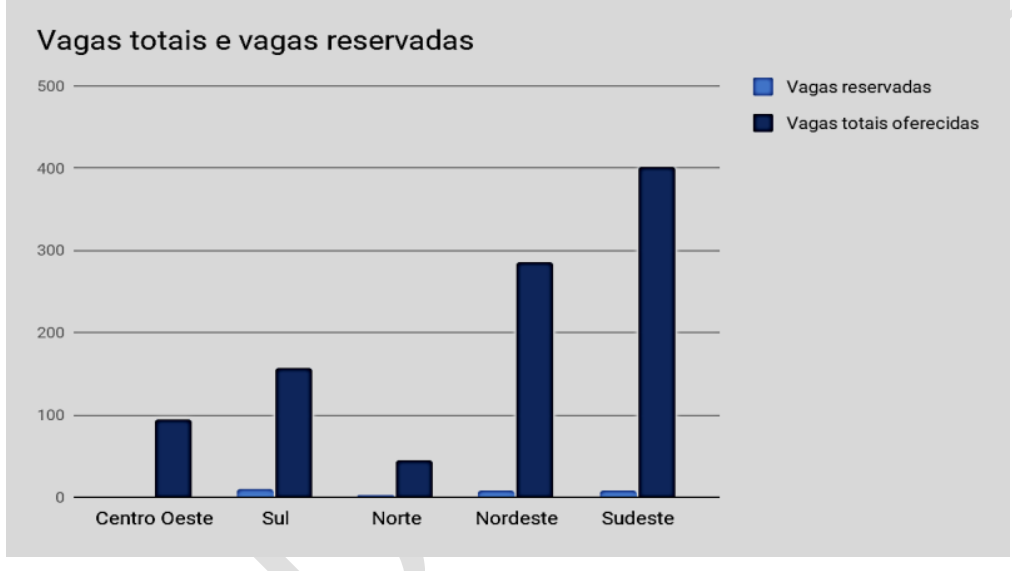

Fonte: Elaborado pelas autoras.

Cabe destacar que dois colégios vinculados à UFSC (CAp e NDI), o da UFPA e o da UFU mantiveram a reserva de vagas também na lista de espera. Sobre os percentuais de reserva/listas de espera, constata-se: $19 \%, 20 \%, 10 \%$ e 50\%, respectivamente, sendo os valores mais altos do que os das vagas totais. Esses dados revelam o quanto a demanda por acesso ainda é urgente, tornando explícita a necessidade de ampliação de vagas para os estudantes públicoalvo da educação especial em ensino regular no sistema federal de ensino.

Diante dos resultados apresentados, nota-se que ainda é uma lacuna conhecer o que está sendo produzido sobre educação inclusiva nos Colégios de Aplicação federais, uma vez que eles têm como papel auxiliar na formação docente e inovações pedagógicas. Observa-se que há uma política ainda a ser consolidada para os colégios federais. 
Além disso, faz-se necessário adotar medidas e práticas para a implementação de políticas que incentivem a produção e a pesquisa acadêmica na área, proporcionando um debate mais amplo, capaz de trazer reflexões junto aos docentes e discentes, almejando uma educação de qualidade e igualitária.

\section{Considerações indicativas}

A educação escolar, como espaço-tempo de formação humana, socialização e sistematização de conhecimentos, apresenta-se como uma área central para a realização de intervenções positivas na superação de preconceitos, estereótipos e discriminação. Portanto, o cumprimento da legislação existente e ainda a concretização de práticas pedagógicas baseadas na educação para e na diversidade demandam uma perspectiva emancipatória. Como se trata de um tema arraigado historicamente na estrutura social, cultural, política e pedagógica do país, seria um equívoco interpretar que a sua efetivação como política pública em educação, bem como a superação dos seus limites de implementação estivessem restritos ao campo educacional e isolados em si mesmos. É por essa razão que uma pesquisa, como a apresentada neste artigo, faz-se necessária para dimensionar o estado em que se encontra a temática e verificar como está sendo realizado o ingresso e a permanência de estudantes com deficiência no sistema de ensino público federal.

Nesse contexto, compreender a produção acadêmica dos Colégios de Aplicação Federais e as formas de ingresso dos estudantes público-alvo da educação é um importante caminho para entender como a pesquisa no Brasil enfrenta a questão da educação especial na perspectiva da educação inclusiva, visto que essas instituições são, de acordo com o MEC, espaços para formação docente e fomentação da pesquisa. Além disso, analisando o cenário legislativo brasileiro, tem-se a reserva de vagas para deficientes como um marco no acesso democrático à educação, por isso, é relevante entender como os CAps estão posicionando-se em relação à inclusão desses alunos.

Diante disso, este artigo procurou trazer apontamentos consideráveis no que diz respeito ao funcionamento da educação pública no âmbito federal, indicando uma necessidade de implementação da política de reservas de vagas de forma mais contundente nas instituições de 


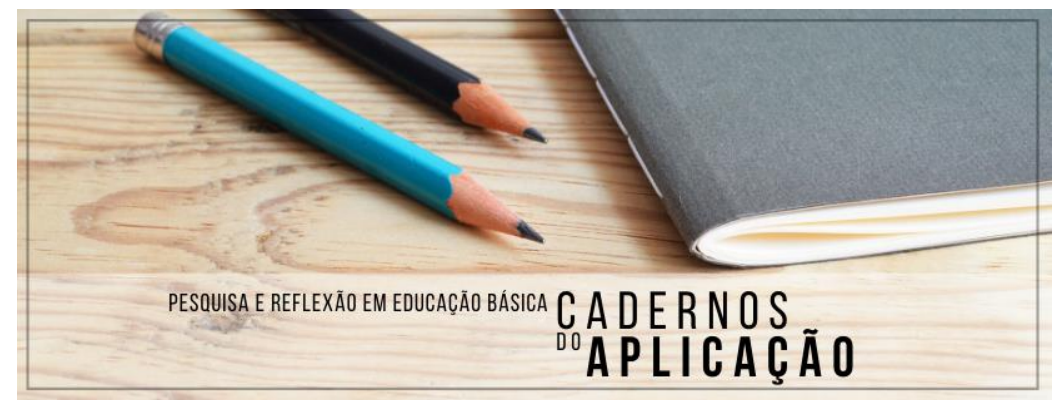

Cadernos do Aplicação

https://seer.ufrgs.br/CadernosdoAplicacao

Publicação Ahead of Print

ISSN 2595-4377 (online)

Porto Alegre | jul-dez. 2021 | v.34 | n.2

ensino público, além de promover uma discussão acerca do fomento e incentivo à pesquisa sobre educação especial na perspectiva da educação inclusiva. Dessa forma, acredita-se que a divulgação desses resultados preliminares irá contribuir para o debate e reflexão de pesquisadores e professores que atuam nos Colégios de Aplicação federais.

Partimos do pressuposto de que há necessidade de entender de que modo a inclusão educacional tem se dado em nosso país. Embora a inclusão não seja um fenômeno recente, ainda há muitas dúvidas a respeito desse processo no contexto educacional. Este estudo tem envidado esforços que podem ajudar a compreender algumas dessas dúvidas e estabelecer alguns parâmetros para pensarmos em respostas para os principais questionamentos. Além disso, a falta de estudos na área educacional também justifica a existência desta investigação.

Desde o início de 2018, foram levantadas e reunidas informações que permitiram traçar um perfil panorâmico dos Colégios de Aplicação, informações públicas, armazenadas em meio digital, disponíveis nas páginas webs de cada CAp. Os aspectos relacionados ao retrato do atendimento em âmbito nacional não podem ser vistos em outra publicação ou produção existente no país, portanto, existe um caráter de ineditismo neste estudo. Espera-se que os resultados preliminares desta pesquisa possam contribuir para um cenário inclusivo.

\section{Referências}

ARANHA, Maria Salete Fábio. Paradigmas da relação da sociedade com as pessoas com deficiências. Revista do Ministério do Trabalho, XI, n 21, março 2001, pp. 160-173.

BRASIL. Conselho Nacional de Educação (CNE). Resolução do Conselho Nacional de Educação - Câmara Plena (CNE/CP) no 02, de 11 de setembro de 2001. Instituiu as Diretrizes Nacionais para a Educação Especial na Educação Básica.

BRASIL. Diretrizes Nacionais para Educação Especial na Educação Básica. Brasília: MEC, 2001.

BRASIL. Ministério da Educação. Base Nacional Comum Curricular. Brasília, 2018.

BRASIL, 2015, Lei n. 13.146, de 6 de jul. de 2015. Lei Brasileira de Inclusão da Pessoa com Deficiência. Disponível em: http://www.planalto.gov.br/ccivil_03/_Ato20152018/2015/Lei/L13146.htm; acesso em: 10 de maio de 2019.

BRASIL, Ministério da Educação, (1997). Parâmetros Curriculares Nacionais para o Ensino Fundamental. Brasília, MEC/SEF. 


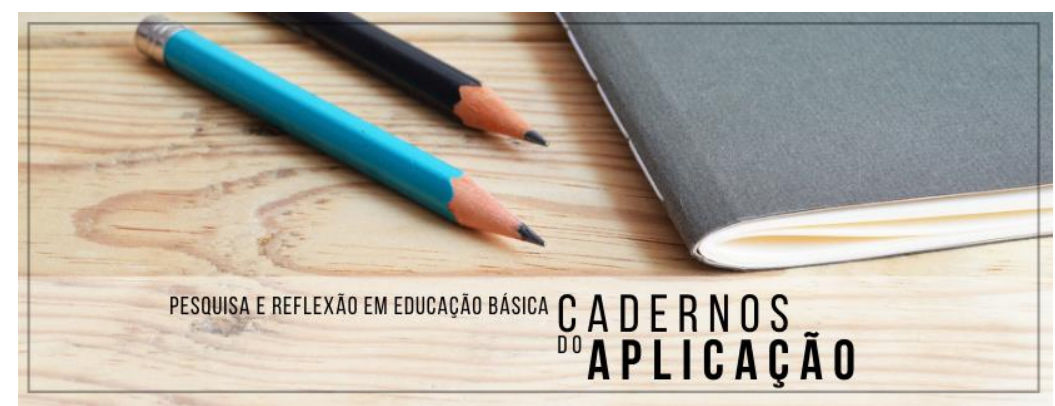

Cadernos do Aplicação

https://seer.ufrgs.br/CadernosdoAplicacao

Publicação Ahead of Print

ISSN 2595-4377 (online)

Porto Alegre | jul-dez. 2021 | v.34 | n.2

CARVALHO, Rosita E. Escola Inclusiva: a reorganização do trabalho pedagógico. Mediação: Porto Alegre/RS, 2008.

DUTRA, Claudia Pereira. Política Pública de educação especial. Revista Aprendizagem. Pinhais, n. 8, p. 24-28, set./out. 2008.

FERREIRA, Maria Elisa Caputo; GUIMARÃES, Marly. Educação inclusiva. Rio de Janeiro: DP\&A, 2003.

FLICK, Uwe. Introdução à Pesquisa Qualitativa (3a ed., J. E. Costa, Trad.). São Paulo: Artmed. (2009).

FOREST, Marsha.; PEARPOINT, Jack. (1997). Inclusão: um panorama maior. In: MANTOAN, Maria Tereza Eglér, et al. A integração de pessoas com deficiência: contribuições para uma reflexão sobre o tema (p.138). São Paulo: Memnon.

GLAT, Rosana (org). Educação Inclusiva: cultura e cotidiano escolar. Rio de Janeiro: 7 letras, 2007.

GLAT, Rosana; PLETSCH, Márcia Denise. Inclusão escolar de aluno com necessidades educacionais especiais. 2 ed. Rio de Janeiro: EdUERJ, 2012. (Série Pesquisa em Educação).

LÜDKE, Menga; ANDRÉ, Marli Eliza Dalmazo Afonso de. Pesquisa em educação: abordagens qualitativas. São Paulo, Editora Pedagógica e Universitária, 1986. 99p.

MANTOAN, Maria Teresa Eglér. Sobre o especial na e o especial da educação - breves considerações. In: Ensaios Pedagógicos: Ministério da Educação, Secretaria de Educação Especial, p. 49-54, 2007.

PLETSCH, Márcia Denise. Educação especial e inclusão escolar: uma radiografia do atendimento educacional especializado na Baixada Fluminense. Revista de Ciências Humanas e Sociais da UFRJ, Seropédica (RJ), 2012, pp. 31-48.

RODRIGUES, David. Questões preliminares sobre o desenvolvimento de políticas de Educação Inclusiva. Inclusão - Revista de Educação Especial, v. 4, n. 1, p. 33- 40, 2008.

TEIXEIRA, Beatriz Basto. Por uma escola democrática: colegiado, currículo e comunidade. 2000. (Tese de Doutorado em Educação). São Paulo. USP.

Data de submissão: $15 / 05 / 2021$

Data de aceite: $10 / 08 / 2021$

DOI: https://doi.org/10.22456/2595-4377.114041 